\title{
Effects of verapamil on electrophysiological properties of anomalous atrioventricular connexion in Wolff-Parkinson-White syndrome
}

\author{
R. A. J. Spurrell, D. M. Krikler, ${ }^{1}$ and E. Sowton \\ From the Department of Cardiology, Guy's Hospital, London
}

Using intracardiac recordings of electrical activity and programmed electrical stimulation of the heart, the effect of verapamil has been studied on the conduction times and refractory periods of the anomalous bypass in 8 patients with the Wolff-Parkinson-White syndrome. A minimal effect was found on both antegrade and retrograde conduction times. The refractory period of the anomalous bypass when measured antegradely was shortened in 3 patients, unchanged in $I$, and lengthened in 4. There was a minimal effect on the refractory period when measured for retrograde conduction. A reciprocal supraventricular tachycardia was initiated in 6 patients and in all 6 this tachycardia was terminated after administration of intravenous verapamil. The significance of these findings is discussed with especial reference to the prevention and treatment of dysrhythmias complicating Wolff-Parkinson-White syndrome.

Verapamil has been shown to be an effective antidysrhythmic agent in man (Schamroth, Krikler, and Garrett, 1972). Fleckenstein et al. (1967) and Singh and Vaughan-Williams (1972) have shown that it does not act as a beta-blocking agent or by a quinidine-like effect on the cell membrane but rather by interference with calcium conduction at the cellular level. Roy, Spurrell, and Sowton (1973) using His bundle electrograms and programmed stimulation of the heart showed that the main effect of verapamil on the specialized conduction system in man was to prolong atrioventricular (AV) junctional conduction times, both antegradely and retrogradely, and to lengthen the refractory period of the AV node. Similar findings were reported for antegrade conduction by Husaini et al. (1973). This effect was only partially reversible with atropine. It had very little effect on the remainder of the specialized conduction system. It is probably this effect on the AV node, which is responsible for the termination of supraventricular tachycardias which are due to a reciprocal mechanism within the AV node and which makes verapamil an effective agent in the management of this particular dysrhythmia. This agent has also proved effective in terminating tachycardias associated with the Wolff-Parkinson-

Received 6 September 1973.

1 Present address: The Cardiovascular Division, Royal Postgraduate Medical School, London WI2.
White (WPW) syndrome (Schamroth et al., 1972). The tachycardias in this condition are commonly thought to be due to a reciprocal mechanism in which antegrade conduction occurs by way of the AV node His system and retrograde conduction by way of an anomalous bypass (Wellens, 197I). In this situation verapamil might be expected to terminate the tachycardia by blocking conduction in the AV node (the antegrade part of the reciprocal circuit) and in this way break the reciprocal mechanism. The functional properties of the anomalous bypass in the WPW syndrome have been studied by several workers (Castellanos et al., 1973) and the effects of drugs on the anomalous bypass have also been assessed (Roelandt, Schamroth, and

TABLE I Clinical details of patients

\begin{tabular}{llll}
\hline Case No. & Age $(y r)$ & Sex & Diagnosis \\
\hline I & 28 & M & WPW type A \\
2 & 40 & F & WPW type A \\
3 & 23 & M & WPW type B \\
4 & 39 & F & WPW type B \\
5 & 24 & M & WPW type B \\
6 & 54 & F & WPW type A \\
7 & 36 & F & WPW type B \\
8 & 74 & W & WPW type A
\end{tabular}


Hugenholtz, I972; Wellens and Durrer, 1973). We have studied the effect of verapamil on the anomalous bypass in the WPW syndrome using intracardiac recordings of electrical activity and programmed electrical stimulation of the heart.

\section{Patients and methods}

The clinical details of the patients are given in Table $\mathrm{I}$. Eight patients were studied, 4 male and 4 female. Four patients had type A WPW and 4 patients had type B. All had a documented history of tachycardia except Cases 5 and 7. Informed consent was obtained from all 8 patients who then underwent an electrophysiological study in the post-absorptive non-sedated state. Three bipolar electrode catheters were introduced percutaneously via one or both femoral veins. One catheter was positioned high in the right atrium to record a high right atrial electrogram. One catheter was positioned across the tricuspid valve to record the His bundle electrogram, using the technique described by Scherlag et al. (1969). The His bundle electrogram was recorded at a filter setting of $40-500$ cycles/second. The intracardiac recordings were made simultaneously with leads I, III, VI, and V6 of the surface electrocardiogram. All recordings were made on an 8-channel Elema Mingograph $8 \mathrm{I}$ at a paper speed of $100 \mathrm{~mm} / \mathrm{second}$. The third catheter was positioned either in the atrium or ventricle for atrial or ventricular pacing and inducing single or double atrial or ventricular premature beats.

A Devices $4270^{1}$ stimulator was used for atrial and ventricular pacing. The heart was driven at a constant frequency to prevent changes in excitability or refractoriness due to irregularities in rhythm. Single or double atrial or ventricular premature beats were delivered after every eighth beat of the basic driven rhythm. A variable delay circuit triggered by either the $R$ wave of the surface electrocardiogram or the right atrial electrogram was used so that the premature beats could be delivered in the cardiac cycle at a preset delay following the preceding driven beat.

Conduction time in the anomalous bypass was measured for antegrade conduction from the stimulus artefact of the atrially driven beats to the onset of the delta wave on the surface electrocardiogram. This measurement also represents the conduction time from the stimulus artefact to the onset of ventricular activation, or St-V time. The retrograde conduction time $\left(\mathrm{V}-\mathrm{A}^{\prime}\right)$ in the anomalous bypass was measured from the onset of ventricular activation to the atrial depolarization as seen on the high right atrial electrogram (HRAE). This measurement was obtained during reciprocal tachycardia rather than during ventricular pacing as it was felt that this former measurement gave a more accurate measurement of retrograde conduction in the anomalous bypass, whereas during ventricular pacing it was not possible to say with absolute certainty that the impulse passed from the ventricles to the atria solely in the anomalous bypass; fusion between retrograde conduction by way

${ }^{1}$ Devices Instruments Ltd., Welwyn Garden City, Hertfordshire. of the AV node His system and the anomalous bypass most probably also occurred.

The refractory period of the anomalous bypass was obtained for antegrade conduction in the following manner. The heart was driven from the right atrium at a constant frequency. At this time the paced complex showed a delta wave, and examination of the His bundle electrogram indicated the occurrence of a fusion beat, formed by anomalous conduction and conduction by way of the AV node His system. Progressively earlier premature beats were induced in the cardiac cycle until conduction by way of the anomalous bypass failed and exclusive normal conduction by way of the AV node His system was seen on the His bundle electrogram and surface electrocardiographic leads. The premature beat interval at which this event occurred was taken as the refractory period of the anomalous bypass. The refractory period of the anomalous bypass was obtained for retrograde conduction by driving the right ventricle at a constant frequency and delivering right ventricular premature beats at progressively earlier intervals in the cardiac cycle. The retrograde conduction times $\left(\mathrm{V}-\mathrm{A}^{\prime}\right)$ were found to be constant with progressively earlier ventricular premature beats, indicating that bypass conduction was occurring (with progressively earlier ventricular premature beats, $\mathrm{V}-\mathrm{A}^{\prime}$ times lengthen when retrograde conduction occurs solely by way of the AV node His system). The premature beat interval at which retrograde conduction to the atria failed, or when $\mathrm{V}-\mathrm{A}^{\prime}$ times suddenly increased, was taken as the refractory period of the bypass when measured during retrograde conduction.

TABLE 2 Summary of antegrade conduction times before and after administration of verapamil in 8 patients

\begin{tabular}{|c|c|c|c|c|}
\hline \multirow[b]{2}{*}{$\begin{array}{l}\text { Case } \\
\text { No. }\end{array}$} & \multicolumn{2}{|c|}{ Before verapamil } & \multicolumn{2}{|c|}{ After verapamil } \\
\hline & $\begin{array}{l}S t_{1}-S t_{2} \\
\text { (msec) }\end{array}$ & $\begin{array}{l}S t-V \\
(m s e c)\end{array}$ & $\begin{array}{l}S t_{1}-S t_{2} \\
(m s e c)\end{array}$ & $\begin{array}{l}\text { St-V } \\
(m s e c)\end{array}$ \\
\hline \multirow[t]{2}{*}{$\mathbf{I}$} & 665 & 160 & 665 & 160 \\
\hline & 400 & 160 & 400 & 160 \\
\hline \multirow[t]{2}{*}{2} & 615 & 80 & 615 & 75 \\
\hline & 320 & 80 & 320 & 80 \\
\hline \multirow[t]{2}{*}{3} & 670 & 125 & 670 & 130 \\
\hline & 310 & 130 & 310 & 130 \\
\hline \multirow[t]{2}{*}{4} & 660 & IIO & 660 & 100 \\
\hline & 270 & IIO & 270 & 100 \\
\hline \multirow[t]{2}{*}{5} & 680 & 145 & 680 & 145 \\
\hline & 285 & 150 & 285 & 145 \\
\hline \multirow[t]{2}{*}{6} & 610 & 140 & 610 & 140 \\
\hline & 350 & 140 & 350 & 145 \\
\hline \multirow[t]{2}{*}{7} & 560 & 80 & 560 & 90 \\
\hline & 340 & 85 & 340 & 90 \\
\hline \multirow[t]{2}{*}{8} & 670 & 140 & 670 & 140 \\
\hline & 345 & 140 & 345 & 140 \\
\hline
\end{tabular}

$\mathrm{St}_{1}-\mathrm{St}_{2}$ represents the interval between the stimulus artefact of the last beat of the basic driven rhythm and the stimulus artefact of the induced premature beat.

$\mathrm{St}-\mathrm{V}$, conduction time in milliseconds from the stimulus artefact to the earliest onset of ventricular activation. 


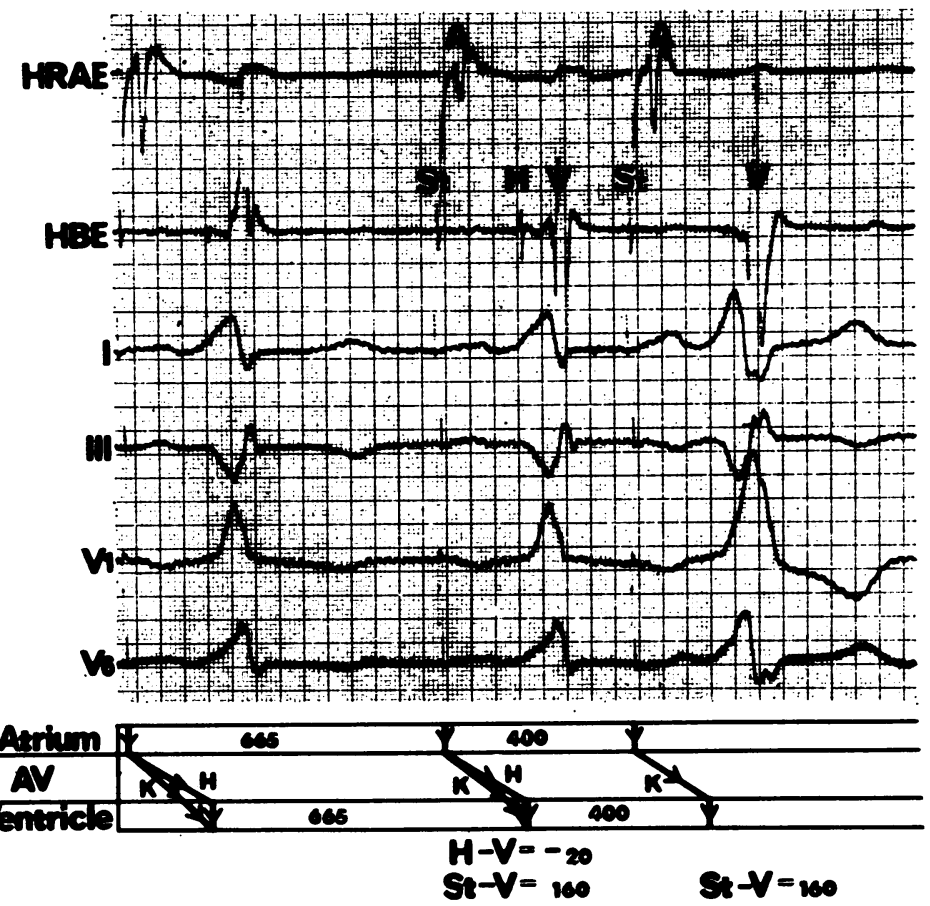

FIG. I Recording obtained from Case I before the administration of verapamil in which the first two beats are right atrial paced beats and the third beat a right atrial premature beat. $A$ conventional ladder diagram is drawn below the recording. HRAE, high right atrial electrogram; HBE, His bundle electrogram; I, III, VI, V6, surface electrocardiographic leads; $A$, right atrial depolarization; St, pacing stimulus artefact; $H$, His bundle depolarization; $V$, ventricular depolarization as seen on the His bundle electrogram; $H-V$, time in milliseconds from the intrinsic deflection of the His bundle depolarization to the earliest onset of ventricular activation; St $-V$, time in milliseconds from the stimulus artefact to the earliest onset of ventricular activation. ( $H, A V$ node His pathway; $K$, Kent or anomalous pathway; $A V$, atrioventricular junction.)

Antegrade and retrograde conduction times and refractory periods of the anomalous bypass were measured before the administration of verapamil in all 8 cases, except Cases 5 and 7 where no tachycardia was initiated and so no $\mathrm{V}-\mathrm{A}^{\prime}$ conduction in tachycardia could be obtained. (Antegrade conduction times and antegrade refractory periods only were measured in these 2 patients before and after the administration of verapamil.) The refractory period of the bypass was not measured for retrograde conduction in Cases 2, 3, 4, and 5. Reciprocal tachycardia was initiated by a suitably timed premature beat in Cases $\mathrm{I}, 2,3,4,6$, and 8. Verapamil, ro $\mathrm{mg}$, was then administered intravenously to these patients and in all 6 the tachycardia was terminated 60 to 90 seconds later. The retrograde conduction times $\left(\mathrm{V}-\mathrm{A}^{\prime}\right)$ were measured during termination of the tachycardia, and then antegrade conduction times and antegrade and retrograde refractory periods were measured after the termination of the tachycardia by intravenous verapamil. In
Cases 5 and 7, ro $\mathrm{mg}$ verapamil was administered intravenously despite the failure to initiate a tachycardia, and the antegrade conduction times and antegrade and retrograde refractory periods were determined.

\section{Results}

Fig. I is a recording obtained from Case I. The first two beats are right atrially driven beats with a cycle length of $665 \mathrm{msec}$. The surface electrocardiographic appearances are of WPW type A (positive delta wave and tall $R$ wave in lead VI). The His deflection on the His bundle electrogram occurs $20 \mathrm{msec}$ after the onset of ventricular activation, indicating that these beats are fusion beats with activation of the ventricles by way both of the anomalous pathway and the AV node His sys- 


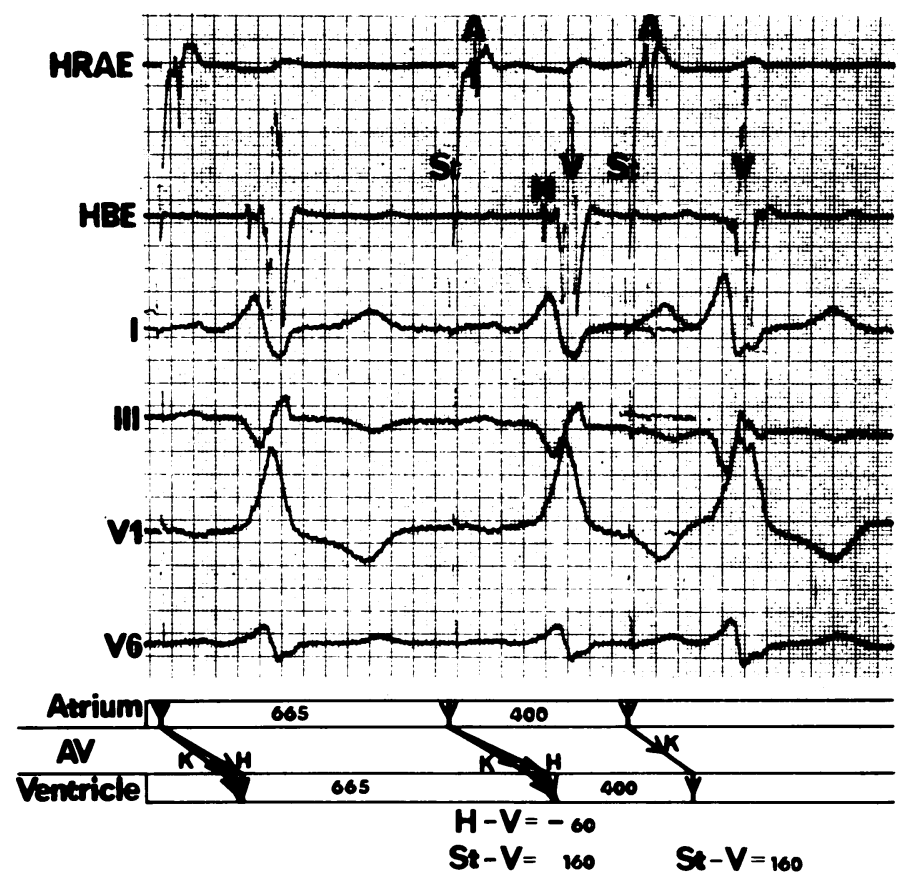

FIG. 2 Recording obtained from Case I during right atrial pacing after the administration of verapamil. The third beat is a right atrial premature beat.

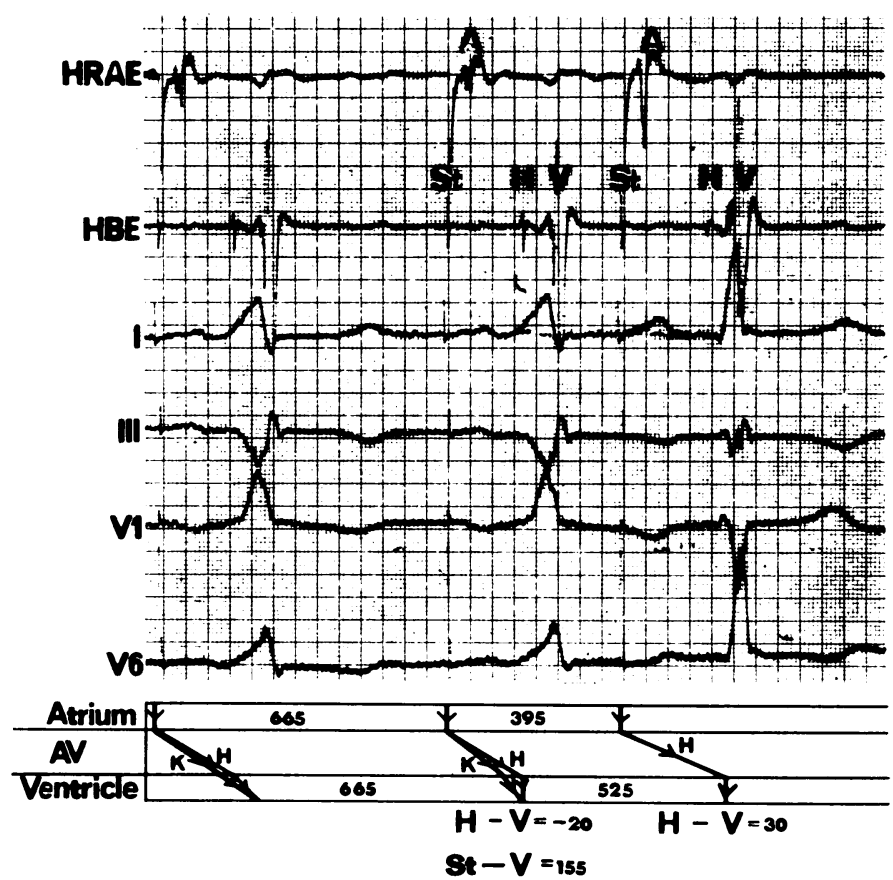

FIG. 3 Recording obtained from Case I before the administration of verapamil in which the third beat occurs sufficiently prematurely to find the anomalous bypass refractory, and normal $A V$ nodal His conduction occurs. 


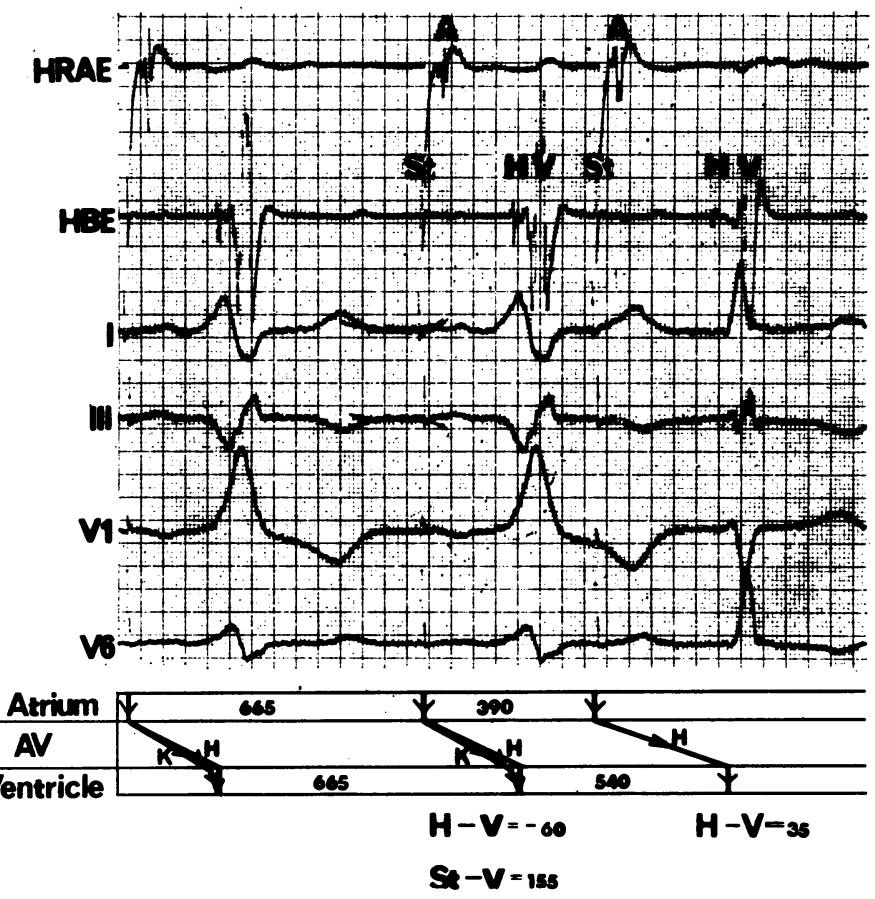

FIG. 4 Recording obtained from Case I after the administration of verapamil in which the third beat is an atrial premature beat occurring at the refractory period of the anomalous bypass as in Fig. 3 .

tem. The conduction time in the anomalous bypass $(\mathrm{St}-\mathrm{V})$ is $160 \mathrm{msec}$. The third beat is an induced right atrial premature beat with a coupling time of $400 \mathrm{msec}$. This beat shows almost exclusive activation of the ventricles by way of the anomalous pathway but the conduction time in the bypass (St-V) is still 160 msec. Fig. 2 is a recording obtained from the same patient after the administration of verapamil. The basic driving cycle length and premature beat interval are still the same as for Fig. I. The conduction time in the anomalous bypass has been quite unaffected by verapamil and remains constant at $160 \mathrm{msec}$. However, conduction in the AV node has been delayed, the His potential now occurring $60 \mathrm{msec}$ after the onset of ventricular activation.

Table 2 summarizes the antegrade conduction time $(\mathrm{St}-\mathrm{V})$ in the anomalous bypass for basic atrially driven beats and atrial premature beats before and after the administration of verapamil in the 8 patients. It will be seen that the variation in conduction time before and after verapamil is never greater than ro msec and may be either an increase or a decrease in conduction time. Out of 16 measurements before and 16 measurements after adminis-
TABLE 3 Summary of refractory periods for antegrade conduction and retrograde conduction in 8 patients before and after verapamil

\begin{tabular}{|c|c|c|c|c|}
\hline $\begin{array}{l}\text { Case } \\
\text { No. }\end{array}$ & $\begin{array}{l}\text { Before vera } \\
\text { Refractory } \\
\text { period } \\
\text { antegrade } \\
\text { (msec) }\end{array}$ & $\begin{array}{l}\text { Refractory } \\
\text { period } \\
\text { retrograde } \\
\text { (msec) }\end{array}$ & $\begin{array}{l}\text { After verap } \\
\text { Refractory } \\
\text { period } \\
\text { antegrade } \\
\text { (msec) }\end{array}$ & $\begin{array}{l}\text { amil } \\
\text { Refractory } \\
\text { period } \\
\text { retrograde } \\
\text { (msec) }\end{array}$ \\
\hline I & 395 & 395 & 390 & 395 \\
\hline 2 & 280 & - & 300 & - \\
\hline 3 & 245 & - & 250 & - \\
\hline 4 & 260 & - & 225 & - \\
\hline 5 & 275 & - & 275 & - \\
\hline 6 & 280 & 250 & 285 & 250 \\
\hline 7 & 310 & 310 & 290 & 310 \\
\hline 8 & 240 & 240 & 280 & 320 \\
\hline
\end{tabular}

tration of the drug the conduction time was unaffected in 8 instances.

Fig. 3 is a recording obtained from Case $I$ before the administration of verapamil. The first two beats are atrially driven beats again with a cycle length of $665 \mathrm{msec}$ and are fusion beats. The third beat 


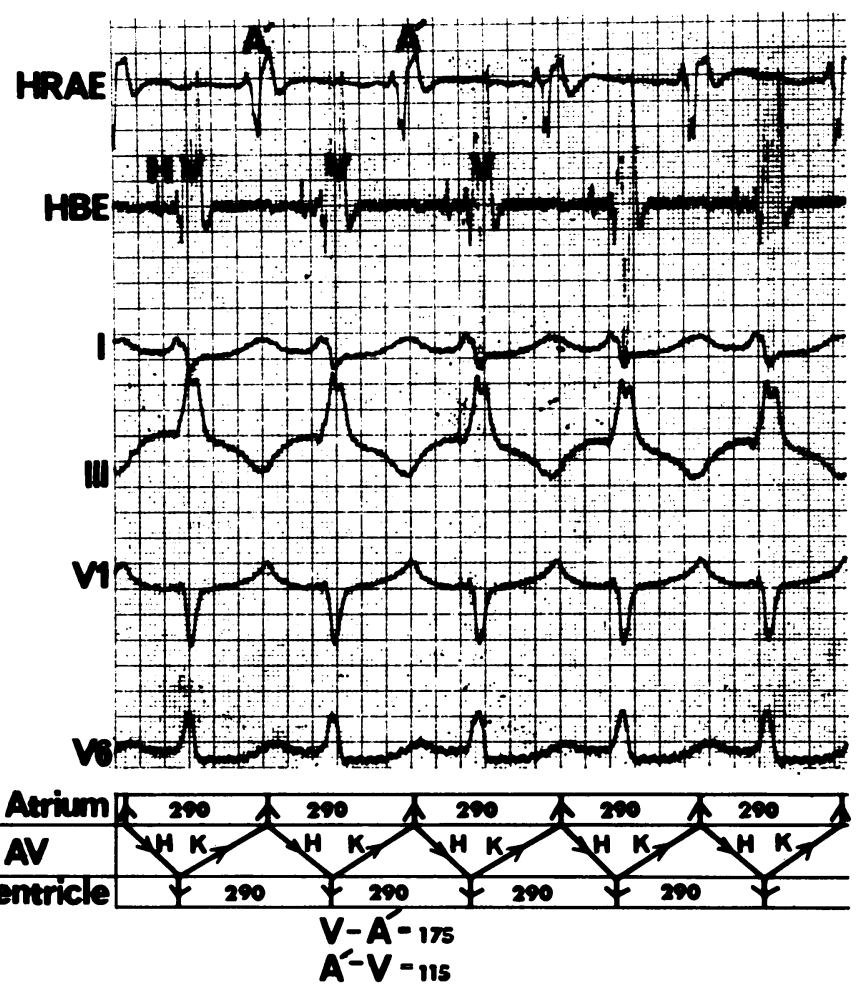

FIG. 5 Recording obtained from Case I during tachycardia. $A^{\prime}$, retrograde right atrial depolarization; $V-A^{\prime}$, retrograde conduction time in milliseconds measured from the earliest onset of ventricular activation to the high right atrial depolarization; $A^{\prime}-V$, antegrade conduction time in milliseconds from the right atrial depolarization to the earliest onset of ventricular activation as seen on the surface electrocardiographic leads. The mechanism of the tachycardia is indicated in the ladder diagram.

TABLE 4 Summary of retrograde conduction times in anomalous pathway during tachycardia in 6 patients

\begin{tabular}{|c|c|c|c|c|}
\hline \multirow[b]{2}{*}{$\begin{array}{l}\text { Case } \\
\text { No. }\end{array}$} & \multicolumn{2}{|c|}{ Before verapamil } & \multicolumn{2}{|c|}{ After verapamil } \\
\hline & $\begin{array}{l}R R \\
(\mathrm{msec})\end{array}$ & $\begin{array}{l}V-A^{\prime} \text { in } \\
\text { tachycardia } \\
\text { (msec) }\end{array}$ & $\begin{array}{l}R R \\
(\mathrm{msec})\end{array}$ & $\begin{array}{l}V-A^{\prime} \text { one beat } \\
\text { before termination } \\
\text { of tachycardia } \\
(\mathrm{msec})\end{array}$ \\
\hline $\mathbf{I}$ & 290 & 175 & 355 & 175 \\
\hline 2 & 315 & 130 & 330 & 130 \\
\hline 3 & 285 & 165 & 310 & 170 \\
\hline 4 & 290 & 195 & 350 & 190 \\
\hline 6 & 330 & 180 & 400 & 180 \\
\hline 8 & 340 & 165 & 430 & 170 \\
\hline
\end{tabular}

$R R=$ cycle length of the tachycardia in milliseconds.

$\mathrm{V}-\mathrm{A}^{\prime}=$ retrograde conduction time in milliseconds from the onset of ventricular activation to the low right atrial depolarization. is an induced atrial premature beat with a coupling time of $395 \mathrm{msec}$ ( $5 \mathrm{msec}$ earlier than in Fig. I). The induced atrial premature beat is conducted solely down the AV node His system as indicated by the normal QRS complex on the surface electrocardiographic leads and the fact that the His deflection precedes the QRS complex by a normal value of $30 \mathrm{msec}$. This atrial premature beat has, therefore, occurred sufficiently early to find the anomalous bypass refractory and the coupling time of this beat therefore represents the refractory period of the anomalous bypass, i.e. $395 \mathrm{msec}$.

Fig. 4 is a tracing obtained from the same patient after the administration of verapamil. It will be seen that the third beat, the induced atrial premature beat, has now been brought back by $5 \mathrm{msec}$ to $390 \mathrm{msec}$ before the refractory period of the bypass is reached, and normal AV nodal His conduction occurs as indicated by a narrow QRS complex with 


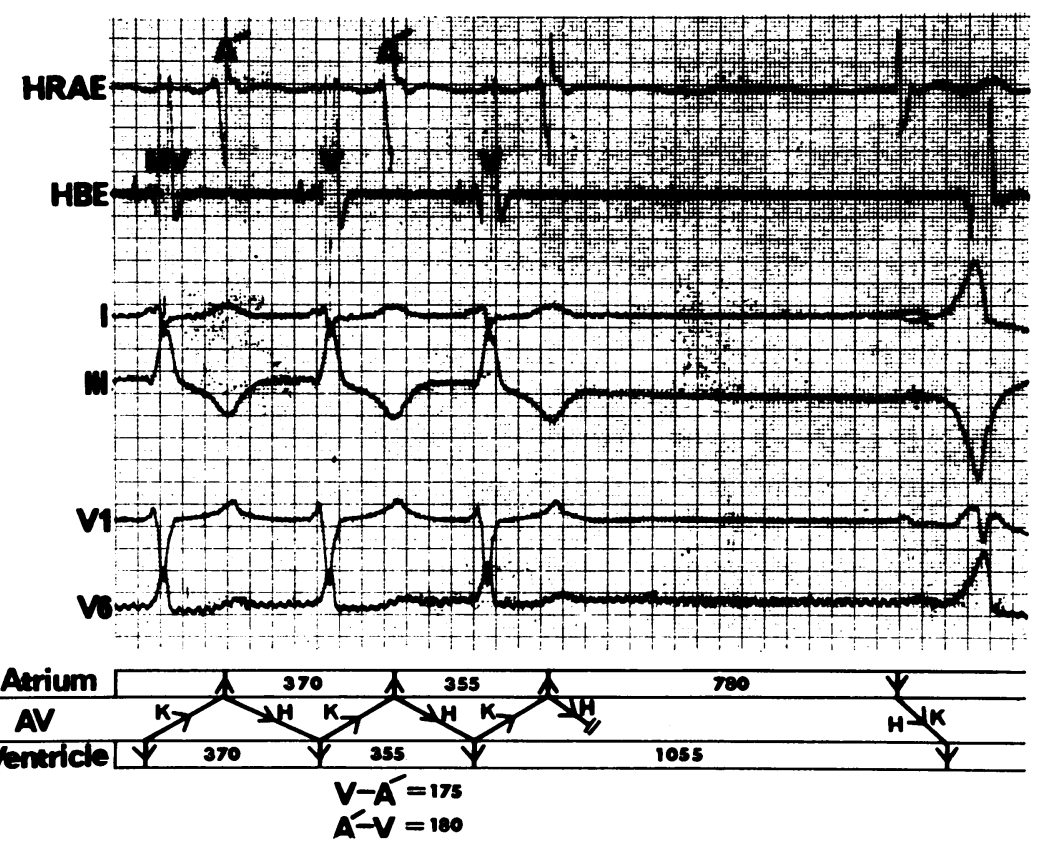

FIG. 6 Recording obtained from Case I showing the termination of the tachycardia after the administration of verapamil. The tachycardia is terminated after the third beat with block in the antegrade pathway.

a normal $\mathrm{HV}$ time of $35 \mathrm{msec}$. The refractory period of the bypass after verapamil is therefore $390 \mathrm{msec}$.

Table 3 summarizes the refractory periods for antegrade conduction and retrograde conduction in all 8 patients both before and after the administration of verapamil. It will be seen that the refractory period for antegrade conduction both before and after verapamil is unchanged in only one patient (Case 5). In 3 patients (Cases 1,4 , and 7) the refractory period was reduced by 5,35 , and $20 \mathrm{msec}$, respectively. In Cases 2, 3, 6, and 8 the refractory period has been lengthened by $20,5,5$, and $40 \mathrm{msec}$, respectively. The refractory period of the bypass when measured retrogradely was recorded in only 4 patients. It remained unchanged in 3 (Cases 1,6 , and 7) and showed a significant prolongation of $80 \mathrm{msec}$ in Case 8.

Fig. 5 is a recording obtained from Case I while in reciprocal supraventricular tachycardia. The tachycardia was supraventricular as indicated by the QRS complex of normal width and configuration preceded by a His deflection with a normal and constant HV time. Retrograde conduction $\left(\mathrm{V}-\mathrm{A}^{\prime}\right)$ in the anomalous bypass is $175 \mathrm{msec}$ and antegrade conduction by way of the AV node His system is II5 msec.
Fig. 6 is a recording obtained from the same patient during termination of the tachycardia after the intravenous injection of $10 \mathrm{mg}$ verapamil. The tachycardia is terminated after the third beat with block in the antegrade pathway. It will be seen that antegrade conduction $\left(\mathrm{A}^{\prime}-\mathrm{V}\right)$ by way of the $\mathrm{AV}$ node His system has lengthened from I $5 \mathrm{msec}$ to I $80 \mathrm{msec}$. This finding is not unexpected; the main effect of verapamil is to slow AV nodal conduction (Husaini et al., I973; Roy et al., 1973). However, the conduction time in the retrograde pathway $\left(\mathrm{V}-\mathrm{A}^{\prime}\right)$ (the anomalous bypass) has been quite unaffected and remains at $175 \mathrm{msec}$.

Table 4 summarizes the retrograde conduction times $\left(\mathrm{V}-\mathrm{A}^{\prime}\right)$ in the anomalous pathway duringtachycardia in the 6 patients in whom a tachycardia was initiated both before verapamil was administered and during the last cycle of the tachycardia before termination after verapamil had been administered. It will be seen that in 3 patients (Cases $I$, 2 , and 6) there was no effect on the conduction time in the anomalous bypass after the administration of verapamil. In 2 patients (Cases 3 and 8 ) the conduction time was increased by $5 \mathrm{msec}$ in each case and in one patient (Case 4) the conduction time was reduced by $5 \mathrm{msec}$. In these 6 patients it will 
be seen that the cycle length of the tachycardia (RR) increased significantly before termination after the administration of verapamil. This change must be entirely due to the effect of verapamil on antegrade conduction in the AV node His system, as only a minimal effect was seen on the retrograde conduction times.

\section{Discussion}

Medical management of the patient with the WPW syndrome involves the prevention or treatment of any associated dysrhythmias. Two main types of tachycardia occur. Firstly there is the circusmovement supraventricular tachycardia which involves antegrade conduction in the AV node His system and retrograde conduction in the anomalous bypass (the reverse direction is exceptional). Any therapeutic agent which is able to block one part of the reciprocal circuit may be useful in terminating tachycardias of this sort. Drugs which act predominantly on the AV node, such as digitalis, are valuable agents for their blocking action on the antegrade part of the reciprocal circuit. In this study the termination of the reciprocal supraventricular tachycardias was due almost entirely to the effect of verapamil in delaying conduction within the AV node, there being very little effect on the conduction time within the anomalous bypass. Similarly, betablocking agents are known to slow AV nodal conduction (Berkowitz et al., 1969; Smithen, Balcon, and Sowton, 197I) and have been shown to be of value in the treatment of reciprocating tachycardias associated with the WPW syndrome (Gibson and Sowton, 1969). Their effectiveness in this situation is most likely due to their action on the AV node. However, Roelandt et al. (1972) showed that the beta-adrenergic receptor blocking drug DL-tiprenolol slowed conduction in both the AV node and the anomalous bypass in patients with the WPW syndrome. This drug could, therefore, be expected to be of particular value in the management of reciprocal tachycardias associated with the WPW syndrome as it delays conduction in both the antegrade and retrograde pathways of the reciprocal circuit. It is, therefore, of value to know the effect of an antidysrhythmic drug on the anomalous bypass as well as the AV node His system.

The other type of dysrhythmia associated with the WPW syndrome is atrial fibrillation or atrial flutter. Here rapid impulses bombard both the AV node His system and the anomalous bypass. In the absence of a bypass, the ventricles are protected from excessively rapid stimulation by the development of physiological block within the AV node but in the WPW syndrome activation of the ventri- cles tends to occur via the anomalous bypass and the frequency is dependent on the refractory period of the bypass. If the refractory period of the bypass is excessively short there is a risk of ventricular fibrillation as a result of activation of the ventricles at high frequency via the anomalous bypass from the fibrillating atria. This may be a possible cause of sudden death in patients with anomalous bypass tracts (Dreifus et al., 1971 ; Spurrell, Krikler, and Sowton, 1973).

The importance of assessing the effect of an antidysrhythmic drug on the electrophysiological properties of an anomalous bypass tract are now apparent. A drug that conspicuously shortens the refractory period of the bypass increases the risk that ventricular fibrillation will complicate atrial fibrillation. Drugs having this property should be used with caution in the WPW syndrome despite their apparent effectiveness in terminating the reciprocating tachycardia associated with this syndrome, the termination being mediated via the drug's effect upon the AV node and not via the effect on the bypass. This situation has been described by Dreifus et al. (197I) in a patient with the WPW syndrome and atrial fibrillation in whom recurrent bouts of ventricular fibrillation appeared to be related to the administration of digoxin. There is evidence that in some cases of the WPW syndrome digoxin shortens the refractory period of the anomalous bypass (Wellens and Durrer, 1973), and this could increase the risk of ventricular fibrillation should atrial fibrillation occur with subsequent conduction to the ventricles at high frequency: this is more likely to occur if the bypass has an inherently short refractory period. Patients with anomalous bypass tracts may well be more liable to develop atrial fibrillation than patients with normal conduction systems (Schamroth and Krikler, 1967), and as such are more vulnerable to the situation described above.

In this paper verapamil has been shown to have only a minimal effect on the antegrade and retrograde conduction times in the anomalous bypass in 8 patients with the WPW syndrome. The effects of this drug on the refractory period of the bypass were variable. When measured antegradely the refractory period was only shortened significantly in 2 patients by 20 and $35 \mathrm{msec}$, respectively. In Case 4 in whom there was a $35 \mathrm{msec}$ reduction in refractory period the resting refractory period was $260 \mathrm{msec}$ which would allow 1 : I conduction at a rate of 232 impulses/minute. After intravenous verapamil the refractory period fell to $225 \mathrm{msec}$ which would allow I:I conduction at a rate of 267 impulses/ minute. A ventricular rate of this level would be liable to cause severe symptoms in an adult patient and there may be a risk of ventricular fibrillation. 
However, in the remaining 7 patients no untoward response to the drug would be expected should atrial fibrillation develop, and indeed in 6 patients either an insignificant decrease or even an increase in the refractory period of the bypass was found. When the refractory period of the bypass was measured during retrograde conduction no decrease was found.

These findings suggest that verapamil is an effective drug in the treatment of reciprocal tachycardias associated with the WPW syndrome. Its effect on the anomalous bypass is such that it can be accepted as a safe drug to use in this condition in most cases but in $\mathrm{I}$ of the 8 patients studied verapamil had an effect on the bypass which could lead to the conversion of a benign to a serious dysrhythmia.

This work was supported by a British Heart Foundation Grant.

The authors would like to thank Devices Instruments Limited for technical assistance.

\section{References}

Berkowitz, W. D., Wit, A. L., Lau, S. H., Steiner, C., and Damato, A. N. (1969). The effects of propranolol on cardiac conduction. Circulation, 40, 855 .

Castellanos, A., Castillo, C. A., Agha, A. S., Befeler, B., and and Myerburg, R. J. (1973). Functional properties of accessory AV pathways during premature atrial stimulation. British Heart fournal, 35, 578.

Dreifus, L. S., Haiat, R., Watanabe, Y., Arriaga, J., and Reitman, N. (1971). Ventricular fibrillation: a possible mechanism of sudden death in patients with WolffParkinson-White syndrome. Circulation, 43, 520.

Fleckenstein, A., Kammermeier, H., Doring, H. J., and Freud, H. J. (1967). Zum Wirkingsmechanismes neuartiger Koronardilatoren mit gleichzeitig Sauerstoffeinsparenden Myokard-Effekten, Prenylamin und Iproveratril. I. Zeitschrift für Kreislaufforschung, 56, 716 and 839.

Gibson, D., and Sowton, E. (1969). The use of beta adrenergic receptor blocking drugs in dysrhythmias. Progress in Cardiovascular Diseases, 12, 16.
Husaini, M. H., Kvasnicka, J., Rydén, L., and Holmberg, S. (1973). Action of verapamil in sinus node, atrioventricular, and intraventricular conduction. British Heart fournal, 35, 734.

Roelandt, J., Schamroth, L., and Hugenholtz, P. G. (1972). Effects of new beta-blocking agent (DL-tiprenolol) on conduction within normal and anomalous atrioventricular pathways of Wolff-Parkinson-White syndrome. British Heart fournal, 34, 1272.

Roy, P. R., Spurrell, R. A. J., and Sowton, E. (1973). The effect of verapamil on the cardiac conduction system in man. Postgraduate Medical fournal. In the press.

Schamroth, L., and Krikler, D. M. (1967). The problem of lone atrial fibrillation. South African Medical fournal, 4r, 502.

Schamroth, L., Krikler, D. M., and Garrett, C. (1972). Immediate effects of intravenous verapamil in cardiac arrythmias. British Medical fournal, $\mathbf{1}, 660$.

Scherlag, B. J., Lau, S. H., Helfant, R. H., Berkowitz, W. D., Stein, E., and Damato, A. N. (1969). Catheter technique for recording His bundle activity in man. Circulation, 39, 13.

Singh, B. N., and Vaughan-Williams, E. M. (1972). A fourth class of anti-dysrhythmic action? Effect of verapamil on ouabain toxicity, on atrial and ventricular intracellular potentials, and on other features of cardiac function. Cardiovascular Research, 6, 109.

Smithen, C. S., Balcon, R., and Sowton, E. (1971). Use of bundle of His potentials to assess changes in atrioventricular conduction produced by a series of beta-adrenergic blocking agents. British Heart fournal, 33, 955.

Spurrell, R. A. J., Krikler, D. M., and Sowton, E. (1973). Concealed bypasses of the atrioventricular node in patients with supraventricular tachycardia. (Abstracts. Young Investigators' Awards Competition.) American fournal of Cardiology, 31, 527.

Wellens, H. J. J. (1971). Electrical Stimulation of the Heart in the Study and Treatment of Tachycardias, p. 70. H. E. Stenfert Kroese, NV/Leiden.

Wellens, H. J. J., and Durrer, D. (1973). Effect of digitalis on atrioventricular conduction and circus-movement tachycardias in patients with the Wolff-Parkinson-White syndrome. Circulation, 47, 1229.

Requests for reprints to Dr. R. A. J. Spurrell, Department of Cardiology, Guy's Hospital, London SEI 9RT. 